\title{
Heart Failure: A New Epidemic of Cardiovascular Disease
}

\section{Insuficiência Cardíaca: Uma Nova Epidemia de Doença Cardiovascular}

Doroteia SILVA $\rrbracket^{1}$, Miguel Angel GOMEZ-SANCHEZ²

Acta Med Port 2016 Jan;29(1):10-11

Keywords: Cardiovascular Diseases; Heart Failure.

Palavras-chave: Doenças Cardiovasculares; Insuficiência Cardíaca.

In contrast to other major forms of cardiovascular diseases (ie., coronary heart disease or stroke) the incidence and prevalence of heart failure (HF) are increasing and the prognosis remains poor. ${ }^{1} \mathrm{HF}$ can be defined as an abnormality of cardiac structure or function leading to failure of the heart to deliver oxygen at a rate commensurate with the requirements of the metabolizing tissues, despite normal filling pressures or only at the expense of increased filling pressures. Coronary artery disease (CAD) is the cause of approximately two-thirds of cases of systolic HF, although hypertension and diabetes are probable contributing factors in many cases.

The problem affects more than 23 million people worldwide. ${ }^{2}$ Approximately $1 \%-2 \%$ of the adult population in developed countries has HF, with the prevalence rising to $\geq 10 \%$ among persons 70 years of age or older, being estimated that HF prevalence will grow up $50 \%$ to $75 \%$ until the year 2030. ${ }^{3}$ This growing prevalence has been attributed to the combination of an ageing population and more effective treatment of its major precursor, coronary artery disease (with drugs, thrombolysis, coronary artery angioplasty and bypass surgery).

The scenario in Portugal is not better. The EPICA study (EPidemiologia da Insuficiência Cardíaca e Aprendizagem), a community-based epidemiological study conducted in mainland Portugal, that involved 365 primary care physicians, who evaluated 6300 primary care attendees aged over 25 years, estimated that overall prevalence of chronic HF in the Portuguese population was 4.4\% (3.69\% $-5.02 \%$ ). Its prevalence varies between $1.36 \%$ in aged 25 to 50 years and $16 \%$ above 80 years. ${ }^{4}$ The major cause/ risk factors for HF in Portugal are hypertension, coronary artery and valvular disease. About half the patients with HF have preserved systolic function. In outpatient clinic, these patients are mainly elderly women; at hospitalization, the number of women is also slight higher (52\%), with a slight prevalence of $\mathrm{HF}$ with systolic dysfunction. ${ }^{4,5}$

Before 1990, the modern era of treatment, $60 \%-70 \%$ of patients died within 5 years of diagnosis, and admission to hospital with worsening symptoms was frequent and recurrent, leading to an epidemic of hospitalization for
$\mathrm{HF}$ in many countries. ${ }^{6}$ In the original and subsequent Framingham cohort, $62 \%$ and $75 \%$ of men and $38 \%$ and $42 \%$ of women, respectively, died within 5 years of being diagnosed with heart failure.

Effective treatment has improved both of these outcomes, with a relative reduction in hospitalization in recent years of $30 \%-50 \%$ and smaller but significant decreases in mortality. ${ }^{7,8}$

A number of factors could have accounted for the steep decline in incident hospitalization and improve survival, including improved HF screening, improved treatment of structural heart disease and also an increased population-based prescription of disease-modifying therapies (inhibitor of angiotensin converting enzyme, $\beta$-blockers, mineralocorticoid receptor antagonists and cardiac resynchronization therapy/ implanted cardioverter defibrillator). But we must remember that from more incidence and prevalence with better survival rates results greater HF epidemic...

Improvements in the prevention and treatment of HF may have had progressive and sustained effects on outcomes at a population level, however individual prognosis and absolute survival remains poor. Absolute survival after a first hospitalization for HF remained poor in both sexes, and in 2002, half of the men were dead at 2.3 years after first hospitalization, and half of the women were dead at 1.7 years. ${ }^{8}$

Part of the responsibility of that phenomena remains on the unsuitability of prescription and non-adherence to treatment measures. In fact, rate of prescription of evidencebased therapies are still suboptimal in patients with HF. ${ }^{8}$ Data obtained from recent records also show that access to an appropriate therapy is still small and very heterogeneous in global Europe. ${ }^{9}$ Doctors are not the only one who contribute to inadequate prescription therapy. Many patients and providers care are poorly understood about the disease, general measures (diet, exercise, physical rehabilitation, self-control) are not met and adherence therapy may be greatly reduced, in part by economic issues but also by factors such as isolation, depression, advanced age and co-morbidity. For all of that, Stewart et al, in their paper

1. Serviço de Cardiologia I. Hospital de Santa Maria. Centro Hospitalar Lisboa Norte. Lisboa. Portugal.

2. Unidad Insuficienza Cardíaca, Hipertensión Pulmonar y Trasplante. Hospital Universitario 12 de Octubre. Madrid. Espanha.

$\triangle$ Autor correspondente: Doroteia Silva. dojreis@hotmail.com

Recebido: 18 de outubro de 2014 - Aceite: 27 de abril de 2015 | Copyright @ Ordem dos Médicos 2016 
published in 2010, concluded that the contemporary impact of HF is similar to that of common forms of cancer in respect to total first-ever hospitalizations, 5-year case-fatality rates, and loss of life in both sexes. ${ }^{7}$

In addition to the cost in human suffering, care for patients with HF places a large economic strain on the health care system. In European Society countries, about 1\% - 2\% of total health care costs are assigned to $\mathrm{HF}$, with $60 \%$ of that related to hospitalizations. ${ }^{10}$ In fact, the reduced quality of life of these patients and greater consumption funds are particularly related with frequent re-hospitalization.

For selected patients with end-stage HF, transplantation remains the gold-standard treatment, with good long-term survival. However, because of the increasing numbers of patients with endstage HF, limited organ donation, and technological advances, mechanical circulatory support with an left ventricle assist device or bi-ventricular assist device is increasingly seen as an alternative for some of these individuals, unfortunately option not widely available

\section{REFERENCES}

1. Roger VL, Go AS, Lloyd-Jones DM, Benjamin EJ, Berry JD, Borden WB, et al. American Heart Association Statistics Committee, Stroke Statistics Subcommittee. Executive summary: heart disease and stroke statistics-2012 update: a report from the American Heart Association. Circulation. 2012;125:188-97.

2. Liu L, Eisen H. Epidemiology of heart failure and scope of the problem. Cardiol Clin. 2014;32:1-8.

3. Mosterd A, Hoes AW. Clinical epidemiology of heart failure. Heart. 2007;93:1137-46.

4. Ceia F, Fonseca C, Mota T, Morais H, Matias F, de Sousa A, et al on behalf of the EPICA Investigators. Prevalence of chronic heart failure in Southwestern Europe: the EPICA study. Eur J Heart Fail. 2002;4:531-9.

5. Sarmento PM, Fonseca C, Marques F, Ceia A, Aleixo A. Acutely decompensated heart failure:characteristics of hospitalized patients and opportunities to improve care. Rev Port Cardiol. 2006;25:13-27.

6. Stewart S, Maclntyre K, Hole DJ, Capewell S, McMurray JJ. More 'malignant' than cancer? Five-year survival following a first admission in Portugal.

In conclusion, HF scenario is still worrying. Although we have advanced, we still have a long way to go.

Like most common forms of cancer, HF exerts a major health burden in respect to age-adjusted rates of first hospitalization, poor overall survival, and premature lifeyears lost. Greater efforts are required to improve quality of life and prognosis of those patients, namely training primary care teams in the management of chronic HF, developing new pharmacological and non-pharmacological HF treatments and finally, applying more investment on networks of HF care, with multidisciplinary teams to manage these complex patients.

\section{CONFLICT OF INTERESTS}

None stated.

\section{FUNDING SOURCES}

None stated.

for heart failure. Eur J Heart Fail. 2001;3:315-22.

7. Stewart S, Ekman I, Ekman T, Odén A, Rosengren A. Population impact of heart failure and the most common forms of cancer: a study of 1162 309 hospital cases in Sweden (1988 to 2004). Circ Cardiovasc Qual Outcomes. 2010;3:573-80.

8. Jhund PS, Macintyre K, Simpson CR, Lewsey JD, Stewart S, Redpath $A$, et al. Long-term trends in first hospitalization for heart failure and subsequent survival between 1986 and 2003: a population study of 5.1 million people. Circulation. 2009;119:515-23.

9. Lainscak M, Cleland JG, Lenzen MJ, Follath F, Komajda M, Swedberg K. International variations in the treatment and co-morbidity of left ventricular systolic dysfunction: data from the EuroHeart Failure Survey. Eur J Heart Fail. 2007;9:292-9.

10. Stewart S, Jenkins A, Buchan S, McGuire A, Capewell S, McMurray JJ. The current cost of heart failure to the National Health Service in the UK. Eur J Heart Fail. 2002;4:361-71. 